\title{
A ressignificação das tradições indígenas da comunidade Sateré-Gavião, no contexto do turismo na cidade de Manaus (Amazonas, Brasil)
}

\section{The resignification of indigenous traditions of Sateré-Gavião community, in the tourism context in Manaus (Amazonas, Brazil)}

\author{
Agnaldo Corrêa de Souza (SOUZA, A. C. de) ${ }^{*}$
}

\begin{abstract}
RESUMO - Este estudo mostra o processo de ressignificação das tradições indígenas reproduzidas na comunidade indígena Sateré-Gavião, da etnia Sateré-Mawé, na zona rural do município de Manaus, Amazonas, Brasil, para atender o mercado turístico. Apresenta o processo inicial e final da atividade turística nessa comunidade, assim como as transformações culturais e sociais ocorridas com a visitação de turistas. Os procedimentos metodológicos partiram da seleção bibliográfica, seguindo o método de análise de abordagem interpretativa por meio da pesquisa de natureza qualitativa e, após a observação e a descrição do objeto de estudo. Os dados coletados foram feitos por meio de entrevista com o representante da comunidade, utilizando-se de questionário semiestruturado. O estudo apresenta-se relevante uma vez que traz para o debate uma temática presente em discussões acadêmicas em instituições públicas e privadas, mas apresentadas e discutidas de forma incipiente na região amazônica. O resultado preliminar mostra que as tradições passam por um processo de ressignificação ao serem apresentadas aos turistas, como forma de captar renda para os comunitários, em que o trabalho tradicional foi modificado para atender o mercado turístico.
\end{abstract}

Palavras-chave: Ressignificação; Tradições; Comunidades indígenas; Turismo.

ABSTRACT - This study shows the process of resignification of indigenous traditions reproduced in the indigenous community Sateré-Gavião, ethnicity Sateré-Mawé, in the rural area of Manaus, Amazonas, Brazil, to serve the tourist market. It presents the initial and final process of tourism in this community, as well as the cultural and social transformation with the tourist visitation. The methodological procedures departed from a bibliographic selection, then it was used the method of interpretive approach analysis using qualitative research and, then the observation and description of the study object. The collected data were made with an interview with the community representative, using a semistructured questionnaire. This study is relevant since it brings to the debate a current issue in academic discussions in public and private institutions, but incipient presented and discussed in Amazon region. The initial result demonstrates that the traditions pass over a process of resignification when presented to the tourists as a form to capture income for the community and that the traditional work was modified to serve the tourist market.

Key words: Resignification; Traditions; Indigenous community; Tourism.

\footnotetext{
* Formação: Graduação em Turismo (Bacharelado) pela Universidade do Estado do Amazonas (UEA), Mestrado em Sociedade e Cultura na Amazônia - PPGSCA da Universidade Federal do Amazonas (UFAM). Pesquisador do Grupo de Estudo, Pesquisa e Observatório Social: Gênero, Política e Poder Gepos (CNPq/UFAM). Bolsista da Fundação de Amparo à Pesquisa do Amazonas (FAPEAM). Endereço físico para correspondência: Rua Coronel Ferreira de Araújo, 125, ap. 206 (Petrópolis). CEP: 69063-000 - Manaus - Amazonas (Brasil). Telefone: (92) 9174-4265. E-mail: ac_correa76@ hotmail.com
} 


\section{INTRODUÇÃO}

A colonização da Amazônia teve o índio como um dos principais personagens na formação sociocultural e, na ocupação da imensidão dos espaços geográficos amazônicos. "A contribuição indígena-cabocla para a ocupação e desenvolvimento da Amazônia foi, no entanto, considerável e sem ela a tarefa de descoberta e exploração teria sido impossível” (BENCHIMOL, 1999, p. 22). O autor complementa que o "conhecer, o saber, o viver e o fazer na Amazônia colonial foi um processo predominantemente indígena".

A partir da aliança com os indígenas, tal processo possibilitou a conquista das florestas, o desbravamento dos inúmeros rios, igarapés, lagos e a superação dos importunos da natureza selvagem para os conquistadores e colonizadores europeus. De acordo com Batista (2007, p. 59), o processo não poderia ter ocorrido sem a aliança com o índio e o seu conhecimento sobre a natureza amazônica, "o que se sabe de fundamental sobre a Amazônia foi por ele revelado", fazendo parte das tradições e costumes das populações atuais.

Os variados grupos indígenas espalhados em solo amazônico possuíam um sistema social, econômico, político e cultural diferentes do de seus conquistadores. Eram caçadores, pescadores, coletores, agricultores, artesãos que se dedicavam na produção de bens para o consumo da própria comunidade, sem a pretensão de produzir em grande escala, nem a obtenção de lucros ou acúmulos de riquezas. Conforme Torres (2005, p. 20), para os grupos indígenas a "própria organização do trabalho apresenta diversidade que não pode ser compreendida apenas sob a lógica do capital”.

As tribos indígenas na Amazônia possuíam um conjunto de tradições, organizações social e cultural e, sistemas de trocas de produtos produzidos pelas comunidades que os diferenciam das relações de consumo no universo capitalista. Para Benchimol (1999, p. 25):

Da biodiversidade da floresta e dos rios, os índios e seus descendentes caboclos e cholos peruanos retiravam tudo o que precisavam para as suas casas, montarias, arcos, flechas, redes, vernizes, tintas, venenos, remédios, alimentos, frutos, amêndoas, drogas, alucinantes para os sonhos, fantasias e visões do pajé e dos xamãs, bebidas para as suas festas e danças, remédios para os curumins e adornos para as suas cunhas, cunhantãs e seus guerreiros. 
A visão de mundo e o entendimento de sua existência eram repassados de geração a geração por meio das histórias, dos mitos e das lendas, constituindo-se como uma sociedade bastante complexa. Este processo entrou em declínio com a chegada das missões religiosas, assim como pelas políticas do Estado português. Para Silva (2012, p. 132), "a resistência dos povos amazônicos contra essas medidas não evitou o desmoronamento da organização comunitária originária”.

Os povos originários da Amazônia tinham sociedades muito diferentes daquelas representadas nos relatos dos primeiro viajantes e cientistas europeus dos séculos XVIII e XIX, que os reduziam a animais selvagens. Gondim (1994, p. 84) escreve que para os europeus "divulgadores do século das luzes", os indígenas "não se encaixavam nos pressupostos universalizantes, porque desdenhavam o ouro, comiam parentes e inimigos, não tinham uma religião estruturada em uma sociedade estribada em preceitos morais naturais, ou oriundos de leis estabelecidas".

Seus conhecimentos, em comparação às ciências da natureza - dominadoras de grande parte das tendências científicas nesta época - não foram respeitados. "A esses valores e culturas foram sendo incorporados, por via de adaptação, assimilação, competição e difusão, novas instituições, instrumentos, técnicas, incentivos e motivações transplantadas pelos seus colonizadores e povoadores" (BENCHIMOL, 1999, p. 13).

Os dilemas vividos pelas populações indígenas no Brasil, assim como na Amazônia, dentro dos campos social, econômico, político e cultural provocou uma grande vulnerabilidade social que, ao assimilar o sistema colonizador predatório, multiplicou o desequilíbrio da vida das comunidades indígenas. Ribeiro (1996, p. 20) destaca que “[...] o processo de assimilação das populações indígenas no Brasil moderno resultou na conclusão de que o impacto da civilização sobre as populações tribais dá lugar a transfigurações étnicas e não à assimilação plena".

Diante deste processo aniquilador da cultura indígena e, também de seus territórios é irreversível a mudança dessa estrutura secular moldada, principalmente, pelos portugueses. Batista $(2007$, p. 59) destaca que "nas fricções interétnicas que se têm processado, a resistência secular e a capacidade de luta redimem o nativo que vai sendo dizimado aos poucos, porém, gloriosamente, enquanto se aproxima a extinção, que é fatal". 
Tal situação nos dias de hoje ganhou força pela globalização da economia. Segundo Santos (2001, p. 18), na globalização "seus fundamentos são a informação e o seu império que encontram alicerce na produção de imagens e do imaginário, e se põem ao serviço do império do dinheiro, fundado este na economização e na monetarização da vida social e da vida pessoal". Este imaginário criado a partir de concepções ideológicas das sociedades dominantes, somente aumenta as diferenças entre outras sociedades, uma vez que se pretende homogeneizar a tudo, sem pelo menos focalizar as diferenças sociais e culturais existentes em âmbito planetário. Isso ocorre com o turismo, através do discurso geopolítico, que é difundido como uma atividade econômica das menos impactantes aos ambientes físicos e culturais, alinhado ao discurso da sustentabilidade ecológica.

Nas últimas décadas deste século, muitas comunidades indígenas ${ }^{1}$ - instaladas a partir do final dos anos 1970 e, início dos anos 1980 (BERNAL, 2009), pelo intenso processo migratório para áreas rurais no município de Manaus começaram a receber turistas. A migração indígena segundo Bernal (2009, p. 29) faz parte da "dinâmica migratória e tipos de estabelecimentos diferentes (que) marcam o percurso de cada uma dessas comunidades". No caso da etnia Sateré-Mawé, Bernal (2009) escreve que as primeiras migrações ocorreram no começo da década de 1970, sendo cada uma "fortemente marcada por um cunho feminino", uma vez que muitas índias foram trazidas pelos antigos funcionários do extinto Serviço de Proteção ao Índio (SPI) e missionários, para trabalhar como domésticas.

Essas comunidades, em decorrência das expectativas do crescente fluxo de turistas através de negociações informais com alguns empreendimentos turísticos, sejam eles hotéis de selva, hotéis urbanos e, embarcações turísticas foram modificando seus hábitos para atender esta demanda cada vez mais crescente ${ }^{2}$. Este processo se intensificou principalmente pelo grande número de hotéis de selva em áreas rurais e,

\footnotetext{
${ }^{1}$ Em Manaus foram mapeadas 54 comunidades urbanas e rurais que têm algum tipo de atividade relacionada com o turismo. Destacam-se as seguintes comunidades: Comunidade Indígena Inhaã-beé (Tarumã), Comunidade Indígena Mawé (Gavião) (Tarumã), Comunidade Indígena Caniço Rouxinol, Comunidade Indígena Aiwaykuru, Comunidade Indígena Yapurar, Comunidade Indígena Yapurar e comunidade de Nossa Senhora do Livramento na reserva ambiental do Tupé (COSTA NOVO, 2011).

2 Durante pesquisa de campo, a partir da fala do representante da comunidade, foi interpretado que as negociações entre tais empreendimentos, não ocorriam de maneira formal com contratos escritos e certificados em cartórios. No entanto, o trabalho realizado pelos membros da comunidade como: a organização do espaço para apresentação de danças e rituais para o recebimento de turistas e visitantes, configura-se como uma mudança dos hábitos da cultura indígena da etnia Sateré-Mawé.
} 
pela proximidade com a capital do Estado do Amazonas (Brasil), que recebe uma considerável demanda de turistas nacionais e estrangeiros. Segundo a Secretaria de Planejamento do Estado do Amazonas - SEPLAN (AMAZONAS, 2011), em Manaus existem 57 hotéis de selva, sendo que no período de 2005 a 2011, estes hotéis receberam uma média de 244.451 hóspedes, entre estrangeiros e nacionais.

O turismo por sua vez manifesta-se como uma estrutura estruturante transformando os espaços físicos e geográficos para produzir oferta de produtos baseados em uma nova cultura. Para Bourdieu (2007, p. 14), "é na correspondência de estrutura que se realiza a função propriamente ideológica do discurso dominante, intermediário estruturado e estruturante, que tende a impor a apreensão da ordem estabelecida como natural". Essa correspondência se apresenta como um processo dinâmico tal qual o fenômeno de geração de tradições apresentado por, Grünewald (2001), em comparação à criação de substância histórica ou cultural que vai ser operada pelo grupo criador em sua etnicidade.

Por outro lado, existe um lado ambivalente nesta relação de produção; de um lado a lucratividade das empresas na comercialização da cultura produzida pelas comunidades e, por outro, o turismo aparece como solução em curto prazo dos problemas sociais e econômicos vividos por essas comunidades indígenas. Para Weber (2004, p. 48):

\footnotetext{
Atualmente a ordem econômica capitalista é um imenso cosmos em que o individuo já nasce dentro e que para ele, ao menos enquanto indivíduo, se dá como um fato, uma crosta que ele não pode alterar e dentro da qual tem que viver. Esse cosmos impõe ao individuo, preso nas redes do mercado, as normas de ação econômica.
}

A execução de atividades turísticas em terras ou comunidades indígenas no Amazonas, por ser um elemento novo do ponto de vista econômico coloca em risco a histórica relação entre o homem, a natureza e a cultura nesses territórios pelo fato das comunidades indígenas e tradicionais serem vulneráveis às transformações produzidas por essas atividades econômicas. A busca pela emancipação dos conflitos e questões indígenas frente às suas vulnerabilidades levou à mobilização política e social dos grupos indígenas na cidade, criando associações como processo facilitador para adquirir recursos financeiros e conquistar seus direitos na cidade. Conforme Bernal (2009, p. 20), "as organizações indígenas oferecem visibilidade às etnias no jogo social urbano 
representando (re-apresentando) os grupos étnicos tanto perante a sociedade em geral quanto perante eles mesmos e sua consciência étnica [...]". A partir dessas associações todas as atividades desenvolvidas pelas comunidades são realizadas mediante a aceitação de seus membros.

Bernal (2009, p. 29), ainda afirma que "alguns grupos criaram suas próprias organizações; enquanto outros se mantêm voluntariamente num estado de 'desorganização organizada' como forma de resistência e de afirmação e autonomia cultural". É frequente ver indígenas na cidade de Manaus vendendo seus artesanatos em feiras e praças públicas, eventos de faculdades públicas e privadas atuando como guias de turistas em hotéis de selva e, apresentando suas tradições nas sedes desses empreendimentos ou em suas comunidades, tanto na cidade como em área rural.

Para Marx Weber (2004) "o dinheiro pode gerar dinheiro e seus rebentos podem gerar ainda mais e assim por diante" e para os indígenas que vivem em comunidades na periferia e na zona rural do município de Manaus, a utilização da sua cultura como atrativo turístico promove a geração de renda em consequência da entrada de turistas em suas comunidades ${ }^{3}$. Deste modo, as suas tradições passam por um processo de ressignificação, pois aquilo que é tradicional para os indígenas passa a ser organizado para atender às necessidades do mercado turístico.

A economia indígena destacada como economia de subsistência, não pode ser sustentada fora de seus territórios tradicionais. Tradições como pescar, caçar e plantar são mais escassas nas pequenas áreas das comunidades ao entorno da cidade de Manaus. Com o turismo, este processo também está mudando o sistema de trabalho dos indígenas, uma vez que eles operacionalizam suas atividades para atender um sistema diferente das suas tradições, mesmo organizando seus sistemas de trabalho de maneira tradicional. A mudança ocorre em virtude das negociações entre os operadores da atividade turística, hotéis de selva e as comunidades indígenas sediadas ao longo do rio Negro e seus afluentes no município de Manaus, Amazonas.

Conforme afirma Capra (2006, p. 167), a economia faz parte "[...] de todo um contexto ecológico e social: um sistema vivo composto de seres humanos em contínua

\footnotetext{
${ }^{3} \mathrm{O}$ desenvolvimento de atividades alinhadas ao turismo em comunidades indígenas transforma os espaços físicos e culturais para serem apresentados como atrativos turísticos e ainda cria uma nova cultura ou revitaliza àquelas já em desuso por estarem fora de seus territórios originais, trazendo benefícios econômicos para toda a comunidade.
} 
interação com seus recursos naturais, a maioria dos quais, por seu turno, constituída de organismos vivos". No turismo, o processo de interação entre os elementos que compõem a sua cadeia produtiva estão organizados de forma sistêmica, a descontinuidade caso ocorra produzirá um desequilíbrio no conjunto das relações ambientais (ecológico, social, econômico, cultural) (BENI, 1998). Esse processo provoca a descaracterização dos ambientes utilizados e potencializados como oferta turística; é imprescindível para este caso um processo de planificação desses espaços (BONALD NETO, 1995; BOULLÓN, 1997).

Neste contexto, revelam-se as dimensões sociais e culturais diante das transformações concebidas pela prática do turismo em comunidades indígenas. As tradições indígenas e a sua dinâmica cultural modelam a sua cultura para serem apresentadas como produto da oferta turística e, deste modo, é negociado dentro da economia globalizada do turismo de forma informal entre comunidades indígenas e empreendimentos turísticos na cidade de Manaus, Amazonas. Estes aspectos aparecem como estratégias de sobrevivência e uma incipiente forma de empreendedorismo indígena, e, também são postas como reafirmação identitária e luta pelos direitos dos grupos indígenas nas comunidades instaladas nas periferias e zona rural das grandes cidades.

O objetivo deste artigo é mostrar o processo de ressignificação das tradições como danças, rituais, músicas, pesca, caça, artesanato, entre outras que estão sendo produzidas para atender o mercado turístico e, por conseguinte, gerar renda para as comunidades. Destaca também a atividade turística no processo de globalização e focalização local dentro da esfera global. Ainda apresenta o processo inicial e final da atividade turística dentro da comunidade indígena Sateré-Gavião ${ }^{4}$, pertencente à etnia Sateré-Mawé, migrantes da Terra Indígena Andirá-Marau, localizada entre os

\footnotetext{
${ }^{4}$ A comunidade indígena Sateré-Gavião, está localizada no igarapé do Tiú, afluente do rio Tarumã-Açú, composta por grupo indígena da etnia Sateré-Mawé vindos da Terra Indígena Andirá-Marau. Até 2008 essa comunidade era denominada de comunidade Mawé, para diferenciar-se de outra comunidade da mesma etnia e, pertencente à mesma família de origem, localizada na mesma margem do rio Tiú. Atualmente seus comunitários se autodenominaram de comunidade Sateré-Gavião, devido ao clã da família de origem ao qual pertencem os comunitários. É constituída de 12 famílias, 49 pessoas entre crianças e adultos, que vivem do subemprego na cidade e da renda dos programas sociais, esporadicamente utilizam suas tradições para atrair turistas na comunidade como forma de ajudar na renda familiar. São grupos que ainda mantêm algumas tradições como o ritual de passagem da Tucandeira (Pesquisa de Campo, 2013).
} 
municípios de Maués, Barreirinha e Parintins, no estado do Amazonas e de Juruti no estado do Pará.

Os procedimentos metodológicos partem da seleção bibliográfica em revistas especializadas, artigos, dissertações e teses contendo informações que contribuíram para o direcionamento teórico-metodológico. Como método de análise utilizou-se da abordagem interpretativa, seguindo o movimento de flexão, compreensão e entendimento do objeto estudado, através do olhar, do ouvir e do escrever, alinhado a etnografia (CARDOSO DE OLIVEIRA, 2006). A etnografia engloba também os métodos e técnicas, além de "estabelecer relações, selecionar informantes, transcrever textos, levantar genealogias, mapear campos, manter um diário, e assim por diante" (GEERTZ, 2008, p. 4).

A pesquisa é também de natureza qualitativa, têm-se também o critério de "esclarecimento de uma situação para uma tomada de consciências [...]" (CHIZZOTTI, 2001, p. 104). A coleta de dados foi por meio da pesquisa de campo pela observação não participante durante oito visitas na comunidade Sateré-Gavião e, pela observação da região onde se encontram alguns hotéis de selva. Foram feitas entrevistas com o dirigente da comunidade, por meio da utilização de um roteiro de entrevista semiestruturado onde foi possível descrever os dados para depois interpretá-los.

Considera-se que o artigo apresenta-se relevante, uma vez que traz para debate uma temática presente em discussões acadêmicas e em instituições públicas e privadas, mas apresentadas e discutidas de forma incipiente na região amazônica. Contêm uma problemática que se preocupa com a sobrevivência das populações indígenas e a preservação das suas características étnicas, dessa forma tornando-se relevante para a sociedade como um todo. Revela um universo ainda pouco explorado no mundo acadêmico cientifico, podendo servir de base para outros estudos.

\section{COMUNIDADES INDÍGENAS E TURISMO}

Após a Segunda Grande Guerra Mundial várias mudanças sociais, políticas e econômicas transformaram o mundo. Segundo Barretto (2003, p. 54), “depois de 1945, a internacionalização da economia no mundo ocidental, por meio dos investimentos 
feitos pelos Estados Unidos na Europa arrasada [...] trouxeram a formação de mercados de consumo de massas globais [...]”. A autora também afirma que o turismo favorecido por essas mudanças emerge com pujança, com destaque para os avanços tecnológicos nos meios de transporte, melhoria nos serviços em hospedagem, alimentação, estabilidade social dos países industrializados, valorização ambiental e cultural dos destinos visitados, constituindo-se como fenômeno social marcante na história da humanidade.

$\mathrm{Na}$ conjectura planetária atual em relação aos movimentos ambientais que defendem a conscientização do uso dos recursos naturais, visando à sustentabilidade, a atividade turística ganha grande evidência. Diante disso, o turismo aparece também como solução, talvez a curto ou longo prazo, aos problemas deferidos pelo modelo empreitado pelo padrão das sociedades pós-modernas ${ }^{5}$ e, por se apresentar como atividade menos impactante ao ambiente natural e cultural das sociedades humanas.

Ao contrário do que se comenta a respeito dos benefícios da atividade turística, os elementos (físicos e culturais) utilizados para atender a cada tipo de demanda turística, são transformados e adaptados de acordo com cada tipologia do turismo como turismo de sol e praia, ecoturismo, turismo rural, turismo cultural, entre outros. Em cada tipologia, a transformação dos ambientes naturais e culturais para a recepção de turistas e visitantes é inevitável, principalmente em função da produção do capital e na absorção do lucro advindas da atividade turística. Rodrigues (1999, p. 43) enfatiza que:

\begin{abstract}
Não se pode deslocar a análise da atividade turística atribuindo-lhe potencial de sustentabilidade sem levar em conta que é uma atividade econômica, que produz (e consume) mesmo tendo como pressuposto 'consumir' paisagens, territórios, em ambientes considerados restauradores ou de descanso para os indivíduos ou mesmo pequeno grupos. É preciso considerá-la articulada com os elementos gerais da produção e do consumo.
\end{abstract}

A importância do turismo para o desenvolvimento mundial, principalmente diante de suas contribuições e ao seu crescimento nos últimos anos deve ser analisada a partir da cadeia produtiva que o compõe, e também pelo "pilar da regulação - Estado,

\footnotetext{
${ }^{5}$ Para Santos (2002, p. 50), a modernidade se traduzia em um ambicioso projeto revolucionário, mas com contradições internas. O autor comenta que ela abriu uma vastidão de possibilidades de inovação social e cultural, contudo, a complexa parte integrante de seus elementos tornou-se impossível sua execução. Ainda, que a modernidade pretendia um desenvolvimento harmonioso e recíproco entre o pilar da regulação e o pilar da emancipação, na qual o desenvolvimento mundial estaria fincado na racionalização da vida coletiva e individual.
} 
mercado e comunidade" ${ }^{, 6}$ onde se incluem atrativos turísticos, hospedagem, transporte, alimentação, serviços e as agências governamentais reguladoras. O turismo como fenômeno social na contemporaneidade pode ser "[...] definido como a soma de fenômenos e relações originados da interação de turistas, empresas, governos locais e comunidades anfitriãs, no processo para atrair turistas e outros visitantes" (GOELDNER, 2002, p. 23).

Satisfazer as necessidades de consumo de uma demanda turística coloca em risco a cultura e as tradições das localidades receptoras, uma vez que a atividade turística reage às influências do meio externo, por ser um sistema aberto (BENI, 1998). Deste modo, o turismo “[...] exerce impactos outros igualmente relevantes, notadamente sobre a cultura e o espaço (natural e, ou, social) da área receptora dos turistas [...]" (SOUZA, 1999, p. 17).

$\mathrm{Na}$ verdade, é preciso saber as opiniões dos sujeitos das localidades e o que de fato é interessante para o seu desenvolvimento e não as formas abusivas de planejamentos externos e a distância. Krippendorf (2001, p. 68) destaca que "[...] nesta grande indústria que é o turismo, é evidente que prevalece a escala de valores dos turistas e dos promotores. Pouco importa o que a população local sente, pensa e quer".

De acordo com Leal (2009, p. 242):

\begin{abstract}
Para tratar do atual desenvolvimento do turismo em territórios indígenas é necessário, antes de tudo, desvencilhar-se de percepções românticas que primam pelo distanciamento do primeiro diante do segundo. A verdade é que cada vez mais os povos indígenas têm pensado na atividade turística como uma alternativa sustentável de desenvolvimento local, empreendida a partir de critérios estabelecidos pelos próprios grupos étnicos [...].
\end{abstract}

A procura por desenvolver novos produtos a serem empregados como oferta no mercado globalizado do turismo, tem despertado o interesse de gestores de empreendimentos turísticos, organizações governamentais e não governamentais em realizar o turismo em terras indígenas (SILVA, 2008). A pretensão dos organizadores e planejadores do turismo, talvez com a "utopia" do desenvolvimento sustentável das

\footnotetext{
${ }^{6}$ Santos (1997, p. 57), destaca que o pilar da regulação é constituído por três princípios: o princípio do Estado (Hobbes), o princípio do Mercado (Locke) e o princípio da comunidade (Rousseau). O equilíbrio pretendido entre a regulação e a emancipação obtém-se pelo desenvolvimento harmonioso de cada um dos pilares e das relações dinâmicas entre eles.
} 
comunidades, do meio ambiente, assim como de seu território (espaço vivido) é a promoção da qualidade de vida e a preservação dos espaços naturais.

No entanto, para Juliano e Rabinovici, (2010), as comunidades indígenas e as demais comunidades tradicionais envolvidas nas atividades do turismo sofrem alterações em consequência da reorganização de sua etnicidade para a recepção e o contato com os visitantes. Leal (2009, p. 243) complementa que "[...] o envolvimento dos povos indígenas com o turismo também é necessário relativizar, uma vez que é preciso inicialmente desenvolver uma reflexão sobre como tais povos que têm extraído condições de garantir sua existência nesse cenário capitalista desigual”.

Qual o tipo de turismo, de que forma serão desenvolvidas as suas atividades e, quais serão os benefícios e malefícios para essas comunidades, causam preocupações. Talvez se possa supor que os indígenas acreditem que o turismo possa vir a contribuir para o bem-estar social. É preciso relativizar também a intenção por detrás de muitos promotores, de gestores de empreendimentos e turistas, uma vez que nos territórios de dominação indígena existem além da biodiversidade, riquezas minerais e também riquezas paisagísticas, assim como a localização estratégica para construção de empreendimentos turísticos, como é o caso das comunidades indígenas e tradicionais localizadas ao entorno da cidade de Manaus, Amazonas, nas margens do rio Negro e seus afluentes.

Durante o trabalho de campo, foi observado que a organização do turismo nas comunidades indígenas está sendo feita por eles mesmos. Eles reorganizam sua cultura para ser apresentada durante a visitação de turistas em suas comunidades e ficam na dependência das empresas. As comunidades que trabalham com os empreendimentos turísticos mantém uma relação de subordinação e são dependentes do centro de decisão ou da sociedade dirigente. Deve-se levar em consideração as transformações espaciais advindas da atividade turística, respeitar os direitos dessas populações, o seu processo histórico de ocupação e o padrão cultural solidificado pelos costumes e tradições de cada etnia fixada nesses espaços.

Além do respeito e o compromisso com a ética, a atividade turística deve evitar na sua essência a ameaça externa - catástrofes naturais, mudanças econômicas mundiais, a sazonalidade, o uso das novas tecnologias, entre outras. Para isso é preciso saber que modelo de atividade econômica é ideal para ser colocada em prática e em 
concomitância com as tradições milenares. Não se pode negar o turismo às comunidades tradicionais e indígenas, mas, é preciso saber equacionar o seu uso para o bem social de todos.

Acredita-se que pelas questões ambientais vigentes, essas comunidades tornaram-se momentaneamente condicionadas a manter equilibrada a relação do homem com o meio ambiente, aumentando o interesse pela procura desses lugares na possibilidade de geração de capital para muitos empreendimentos turísticos. Neste sentido, como afirmava Gilberto Pereira da Silva (2008), chefe de posto da Fundação Nacional do Índio (FUNAI) na terra indígena Raposa Serra do Sul em Roraima: eram frequentes os pedidos de gestores de empreendimentos turísticos para utilizarem as aldeias e comunidades indígenas como atrativos turísticos. Ele assinalava que:

\footnotetext{
A primeira discussão formal, na FUNAI, sobre turismo nas terras indígenas brasileiras ocorreu no ano de 1993, através do documento C. I. $\mathrm{n}^{\circ}$ 21/GAB/ADR/FUNAI/MAO, de 14 de abril de 1993, que encaminha a ATA DE CRIAÇÃO DA COMISSÃO ESPECIAL DE TURISMO DA AMAZÔNIA-BRASIL/CENTURA-BRASIL. O Parecer $\mathrm{n}^{\circ} 002$ - DFUNAI/ADR/MAO, de 28 de abril do mesmo ano (SILVA, 2008, p. 3).
}

Identifica-se que a abertura deste novo mercado tem fascinado tanto as agências de turismo, as organizações governamentais e não governamentais, os turistas e a própria comunidade local em desenvolver o turismo nessas áreas (SILVA, 2008). O estudo aqui empreitado toma como base o turismo em territórios indígenas, realizado na comunidade indígena Sateré-Gavião, localizada na região da micro-bacia hidrográfica do rio Tarumã-Açú, no município de Manaus estado do Amazonas, Brasil.

\section{O INÍCIO E O FIM DO TURISMO NA COMUNIDADE SATERÉ-GAVIÃO}

Diferenciando-se dos conceitos e definições técnico-acadêmicos que trazem as questões do tempo, de atividade econômica não remunerada, de uso dos equipamentos e da infraestrutura (apoio, serviços, transporte), foi verificado que o turismo em comunidades indígenas se dá pelas relações existentes entre os comunitários, empresários e turistas nos espaços étnicos. Para o indígena, independente destes 
critérios teóricos, o recebimento de turistas em suas comunidades, mesmo por um período mínimo de tempo é considerado como turismo.

As questões sociais e econômicas de quase todas as comunidades indígenas no município de Manaus têm levado esses grupos a buscarem alternativas econômicas para captação de recursos financeiros como forma de garantir as suas permanências nesses espaços. A venda de artesanato, o trabalho laboral em casas de famílias, a limpeza de terrenos e as apresentações de sua cultura para turistas e visitantes nas comunidades são algumas das estratégias de sobrevivência encontradas pelos grupos indígenas (PEIXOTO; ALBUQUERQUE, 2007).

Verificou-se que o turismo na comunidade Sateré-Gavião foi uma alternativa dos próprios comunitários, a qual surgiu durante a inserção de alguns membros que atuaram como guias, condutores de canoas para focagens de jacarés e em trilhas na floresta dos hotéis de selva, uma vez que passaram a ter maior contato com os turistas. Eles perceberam a partir daí, que poderiam apresentar no espaço da própria comunidade suas tradições para turistas e visitantes. Deste modo, entenderam que o turismo poderia beneficiar todos os comunitários.

Também se constatou que nos hotéis de selva se reproduzem modelos das habitações indígenas em suas áreas e, contratam mão-de-obra indígena juntamente com os não indígenas, para apresentarem aspectos da cultura indígena nesses espaços de maneira teatral. Essas apresentações constituem-se como um produto turístico que complementa a oferta desses empreendimentos. Esses espaços são locais estratégicos reservados em áreas próximas das sedes dos hotéis de selva, para onde os turistas são conduzidos. Nessas localidades tentam reproduzir uma área étnica, onde indígenas de várias etnias se pintam para representar suas tradições, não de forma tradicional, mas organizadas dentro de uma cultura alheia aos seus costumes.

A ideia de trabalhar o turismo na comunidade Sateré-Gavião partiu dos próprios indígenas, como é demonstrado na fala do tuxaua Eliomar da Silva Martins (Tucandeira) (MARTINS, 2013), representante político e religioso da comunidade:

Na época de 2005, né! Nós viemos trabalhando em outros anos, é - com o turismo - vendo como é que a gente poderia fazer nosso artesanato pra, gerar uma renda, né! Ai, nós viemos pesquisando, por exemplo: Ariaú, nós andamos por lá! Trabalhamos meses, ai, não deu certo! Aí viemos pra cá. Aí, foi na época de 2005 que nós viemos pro Tarumã trabalhar com o turismo. Eu descobrir que tinha um hotel de selva aqui - o Amazônia Eco-Park -, beleza, nós vamos tentar. Aí, eu fui lá um dia, chamei o pessoal - seis 
pessoas. Fui lá conheci, eles disseram: - Sim! - A gente trabalha com vocês. Se vocês já quiserem botar alguém pra trabalhar aqui com a gente, da aldeia de vocês que esteja realmente precisando trabalhar a gente tem vaga! Eu (Eliomar) sou um, eu falei, eu aceito trabalhar ${ }^{7}$.

Ele relatou que foi trabalhar como piloto de "voadeira", , onde tinha contato constante com os turistas. Todo esse processo pode ser relacionado às solicitações junto a FUNAI como indica Victor Ferri Mauro (2007), pelas empresas que veem na cultura indígena, assim como nos seus territórios, uma potencialidade de atração turística. Prossegue afirmando que, no entanto, para haver qualquer atividade que envolva os indígenas é preciso ter o consentimento dos grupos étnicos, respeitando a cultura e seus territórios salvaguardando a vida, assim como os direitos dos grupos indígenas.

De acordo com Declaração das Nações Unidas sobre os Direitos dos Povos Indígenas de 29 de junho de 2006, art. 23: “os povos indígenas têm o direito de determinar e elaborar prioridades e estratégias para o exercício do seu direito ao desenvolvimento" (ONU, 2006). O Estatuto do Índio (BRASIL, 1973), Art. 02 § III orienta que é preciso respeitar, ao proporcionar aos índios meios para o seu desenvolvimento, as peculiaridades inerentes à sua condição e $§$ IV - assegurar aos índios a possibilidade de livre escolha dos seus meios de vida e subsistência.

O tuxaua Martins (2013) relatou que, após uma conversa com a gerente do empreendimento, os seus representantes se dirigiram para comunidade. Na época era o período em que as águas estavam baixando, no final do mês de novembro, quando foram conhecer a comunidade. Segundo o tuxaua, três dirigentes, incluindo a gerente do hotel se deslocaram do hotel até a comunidade que fica a menos de quinze minutos de viagem pelo rio Tarumã. Ele ainda contou que a gerente teve boa impressão da comunidade, pois os indígenas tinham feito uma grande recepção com danças, rituais; uma grande festa onde todos os indígenas tinham pintado seus corpos com tinta de jenipapo ${ }^{9}$ para dar boas vindas àquele grupo.

\footnotetext{
${ }^{7}$ Conversação pessoal com o tuxaua Eliomar da Silva Martins, em Manaus, em julho de 2013.

${ }^{8}$ É uma pequena embarcação que recebeu esta denominação na região por se movimentar velozmente sobre as águas dos rios amazônicos. No dicionário eletrônico Houaiss (2007) é denominado de deslizador, que ou o que, movido por hélice aérea, desliza velozmente sobre a água (diz-se de ou embarcação de pequeno calado).

${ }^{9}$ É um fruto comestível, com polpa aromatizada, na qual os indígenas usam a polpa e as sementes que podem ser extraídas um líquido preto usado com tinta para pintar os corpos, principalmente nos festejos
} 
Por meio dos trabalhos desenvolvidos pelos indígenas diretamente com os turistas, seja como pilotos das embarcações, seja como guias nas trilhas nas matas dos hotéis de selva, foi percebido durante a pesquisa de campo, que neste processo houve uma dinâmica cultural nas relações entre os empreendedores do turismo, os indígenas e os turistas. Isso despertou o interesse em desenvolver o turismo na comunidade a partir da apresentação de sua cultura.

Além disso, foi observado que os indígenas organizavam-se não mais de forma tradicional, pois estavam distribuindo as tarefas entre eles, para a entrada na economia do turismo. O trabalho era distribuído entre as famílias e cada indígena fícava responsável em desenvolver uma atividade, mas a atenção maior era para a produção dos artesanatos. Os rituais serviam para atrair a atenção dos turistas e o artesanato era o produto destinado à comercialização.

Produzia-se um sistema econômico onde se tinha os hotéis de selva oferecendo a comunidade como atrativo turístico e os indígenas reproduzindo seus rituais para atrair e chamar a atenção dos visitantes para gerar renda. Contudo, verificou-se existir um desequilíbrio entre hotéis e comunidades, pois os pacotes e quantidade de turistas nas comunidades não gerava lucro efetivo para os indígenas. Este processo é analisado como sendo mais uma atividade econômica de subsistência. Deste modo, à cadeia produtiva do turismo não correspondeu em ações recíprocas entre esses dois elementos hotéis e comunidade.

Neste caso, verificou-se haver uma espécie de "engrenagem fora dos eixos" do sistema, ou seja, o processo de retroalimentação desenvolvido pelos hotéis junto às comunidades, não compensava as perdas diante das interações sociais e o fluxo turístico. Para Krippendorf (2001, p. 96) este tipo de questão desperta o senso crítico dos autóctones, "a resistência se organiza apenas numa segunda fase e pode ser conduzida a uma terceira e última fase, em que se manifesta uma forte vontade política militante em favor de um desenvolvimento moderado e autodeterminante do turismo".

Criou-se uma relação de dependência entre o empreendimento e a comunidade, uma vez que a última se constitui de grupos econômica e socialmente vulneráveis e os espaços vividos passaram por transformações, principalmente de ordem cultural. $\mathrm{O}$ indígena, segundo o tuxaua Martins (2013), passou a ir à cidade com mais frequência

das tradições indígenas ou quando eles reivindicam seus direitos junto às instituições públicas (Adaptado do site <www.arara.fr>). 
para adquirir novos utensílios e produtos tecnológicos. Não houve uma compensação em forma de ações tanto do Estado quanto dos empresários do turismo nesta localidade, o desenvolvimento estava pautado nas possibilidades de venda do artesanato, o trabalho desenvolvido pelos comunitários não era compensatório para toda a comunidade, uma vez que aquela família que não vendesse seus artesanatos, não participava da renda da outra.

O tuxaua Martins (2013) relatou que o grupo sempre reivindicou ação mais efetiva do Estado, um exemplo é o da energia elétrica. Enquanto perto da comunidade há um estaleiro funcionando a menos de quinhentos metros, a comunidade não foi ainda contemplada com este serviço básico. A comunidade possui um pequeno gerador de energia que funciona apenas durante algumas horas da noite e, quando há condições financeiras para compra de combustível.

A cadeia produtiva "cujos processos, atividades, produtos e serviços são articulados entre si, como elos de uma mesma corrente, segundo uma sequência lógica progressiva ao longo de todo o ciclo produtivo" (BRASIL, 2000), não teve em sua produção a complementaridade do desenvolvimento da comunidade. Os elos que poderiam fazer a comunidade se desenvolver econômica e socialmente posicionaram-se distantes para dar respostas às práticas sustentáveis do desenvolvimento do turismo em comunidades de grupos vulneráveis.

O fluxo de visitantes nos espaços rurais no município de Manaus e a aproximação com a urbe, assim como em toda região Metropolitana de forma interacional entre as culturas, também vêm modificando as tradições e o habitus das populações tradicionais (caboclas, ribeirinhas e indígenas). As atividades econômicas globalizantes, no caso do turismo nessas comunidades, precisam de longo processo de maturação tanto das questões voltadas para organização e o planejamento, quanto na administração e contabilidade das entradas e saídas de recursos advindos da atividade turística.

A falta destes conhecimentos e de maturação de todo o processo por parte dos indígenas é prejudicial à manutenção de qualquer atividade econômica e social desenvolvida por eles. Este fato é identificado diante dos acordos entre as comunidades e os empreendedores no princípio do estágio de entrada do turismo na comunidade 
indígena, os quais foram feitos apenas verbalmente, como revela a fala do tuxaua Martins (2013):

\begin{abstract}
Ai eu acertei com o pessoal (comunidade) o que quiserem dar pra gente, a gente aceita. Qual é a proposta deles? Vocês vão aceitar? Ai eles disseram: Nós vamos. Ai eu fui conversar com ela. Dona Carla o que a senhora tem a oferecer pra gente? Aí ofereceram seis cestas básicas de rancho por mês - um sacão grande. Nós éramos sete famílias. Ai, mais a compra do artesanato e outras coisas que nós precisássemos mais. Até nós ganhar nosso dinheirinho com a venda do artesanato. Mas, dava bem! A venda do artesanato dava bem, então ninguém precisou cobrar o hotel.
\end{abstract}

Mesmo não existindo um nível de organização administrativa, este processo dinamizava a comunidade para a atração de recursos por meio do fluxo de visitantes e o interesse dos turistas e empreendedores em relação à comunidade como produto e oferta turística. A interação entre os comunitários em organizarem-se para o outro pode ser percebida durante a primeira visita à comunidade, para solicitar o consentimento de inserção entre os Sateré para realização da pesquisa em junho de 2012.

Foi observado que a área ao redor das casas dos moradores, onde se situa um campo de futebol estava toda ornamentada com palhas de bacuri (Attalea phalerata) ${ }^{10}$, formando um portal de entrada e espalhados pelo campo restos de tochas derramando pequenas nuvens de fumaça, resultado do processo da organização e da apresentação para visitantes da noite anterior. Havia também um jirau, galhos finos de árvores amarrados com cipós de envira ${ }^{11}$ retirados da pequena floresta da comunidade, com dois pedaços de árvores pintados de amarelo. Este pedaço de árvore tinha sido utilizado como alvo dos disparos das zarabatanas e flechas, representando uma parte da cultura indígena utilizada para atrair turistas, alguns empreendedores de atividade econômica e, talvez da comunidade científica.

A dinâmica cultural, "[...] vem gerando novas tradições a serem exibidas como sinais diacríticos na sua etnicidade, mediante o íntimo contato desses índios com um

\footnotetext{
${ }^{10}$ Palmeira nativa encontrada nas matas ciliares da região Amazônia, chegando a 3 a 7 metros de altura. Seus frutos são no formato de coquinhos e se espalham em um único cacho, antes de amadurecerem são cobertos por uma bolsa fibrosa, ao chegar à fase de maturação se enrijece no formato de pequena canoas que são utilizadas no artesanato e na ornamentação de eventos regionais. (Adaptado do site <vivaterra.org.br>.

${ }^{11}$ Segundo o dicionário eletrônico Houaiss (2007), Envira ou embira, é conhecida como embira-branca; embireira, envireira [Encerram dafnina espalhada nas folhas, venenosas para o gado, e nas cascas, de que frequentemente se extraem as fibras da parte interna, para a confecção de cordas e estopa].
} 
sistemático fluxo turístico [...]" (GRÜNEWALD, 2001, p. 8). Hall (2006) escreve que quanto mais as culturas nacionais ficam expostas a influências externas fica mais difícil conservar as identidades culturais ou impedir que elas se tornem enfraquecidas.

A comunidade Sateré-Gavião, por mais que esteja situada do lado oposto à área urbana de Manaus há muitos anos, desde seu estabelecimento na cidade, já passou pelo processo de integração social. Hábitos e costumes são mediados como forma de compensar a perda de não viver em suas terras originárias e por se considerarem grupos distintos à sociedade nacional (RIBEIRO, 1996).

Um exemplo dessa mediação são as habitações, tendo-se observado que mesmo sendo construídas em madeira, com piso batido ou assoalhadas, ainda se faz presente o espírito de coletividade e de comunidade. No horário do almoço, na casa do tuxaua, o peixe fritava na frigideira e o convite era feito a todos que estivessem por perto para se reunirem à mesa. Nesse momento se aproximava da casa um pastor de uma igreja evangélica, trazendo alguns mantimentos que também foram compartilhados entre todos os presentes.

Com o turismo se teve a reafirmação identitária, o resgate das tradições perdidas no processo de integração à sociedade nacional. O grupo indígena da comunidade entrava em acordo uns com os outros e decidiam o que deveria e o que não deveria ser apresentado. Nesse processo, alguns rituais e danças foram relembrados pela memória e informações das raris $^{12}$, tradições estas que apenas eram repassadas de geração a geração nos territórios tradicionais.

Neste aspecto verificou-se que o turismo reacende e revitaliza as tradições que já estavam esquecidas pelo grupo vivendo na cidade e próxima a ela, havendo um processo de readaptação dessas culturas. Parafraseando a fala do tuxaua Martins (2013), mesmo havendo apresentações para o outro, por meio dos elementos identitários ligados a sua cultura e os indígenas atuando de forma organizada tradicionalmente, esse processo estava fazendo com que a cultura Sateré-Mawé resistisse historicamente dentro dos processos transformadores dos espaços urbanos.

Conforme o tuxaua Martins (2013), entre as tradições apresentadas estavam armadilhas na floresta para pegar animais, lançamento de zarabatana, arco e flecha, danças tribais de 10 minutos de duração, a roça, a caça e pesca e o ritual da tucandeira.

${ }^{12}$ Representa os mais idosos da comunidade, tanto homens quanto mulheres. 
Este último elemento além de fazer parte das tradições dos Sateré-Mawé traz consigo a identidade dessa etnia. Segundo Bernal (2009, p. 84), os Sateré-Mawé reverenciam a entrada de um indivíduo na maturidade, "este momento é visto como um evento coletivo que ativa uma rede de expectativas, de atividades e tarefas sociais no ambiente local e intercomunitário marcado pela celebração da festa da Tucandeira".

O ritual da tucandeira já foi mostrado pelas mídias nacional e internacional ao mundo todo, não apenas por ser parte de uma cultura, mas pela complexidade de preparação de todo processo, indo desde a captura das grandes formigas pretas, o enchimento das luvas de palhas tecidas pelos indígenas (saaripé), as dores provocadas pelas ferroadas de várias formigas que duram mais de 24 horas e a resistência indígena como prova de sua bravura, completando deste modo o ritual de passagem para a fase adulta (BERNAL, 2009). Conforme afirma Kapfhammer (2004, p. 111), o ritual representa não apenas a passagem de uma para outra, sobretudo, “[...] o contato (sexual) com a mulher-cobra (simbolizada nas parafernálias ricamente adornadas), encenado no ritual, não só 'impregna' contra riscos à saúde, mas capacita o rapaz a realizar os papeis masculinos da sociedade sateré-mawé tradicional [...]".

A ressignificação das tradições em formato de trabalho capitalista nas comunidades indígenas corresponde "[...] ao artificialismo da existência humana, existência esta não necessariamente contida no eterno ciclo vital da espécie, e cuja mortalidade não é compensada por este último [...]" (ARENDT, 2007, p. 15). No universo preparado para o turista, como indica Arendt (2007), cria-se um mundo artificial de coisas, onde os grupos em sua totalidade readaptam suas tradições como forma de incluir-se na dinâmica da economia capitalista do turismo.

Essa dinâmica apresentada entre os processos de inserção à economia do turismo, assim como na dinâmica cultural e social podem representar tanto pontos positivos quanto negativos. Entre os positivos contatou-se que as rendas das famílias aumentam com a entrada do dinheiro vindo da venda do artesanato, o que produziu melhoria social e a evolução do capital social (engajamento dos comunitários nas tomadas de decisões). Um ponto negativo é a não organização econômica na entrada dos recursos vindos da venda do artesanato, uma vez que cada família produzia seus artesanatos, com isso, existem interesses individuais que superam os coletivos. 
Esses interesses individuais fizeram com que a visitação de turistas deixasse de ocorrer na comunidade. O tuxaua Martins (2013) relatou que alguns membros da comunidade iam para a cidade fazer compras pessoais e não retornavam nos horários combinados, chegando a não realizar apresentações para alguns grupos de turistas organizadas pelo hotel de selva com o qual mantinham relações econômicas. O não comprometimento com toda a comunidade fez com que o tuxaua desfizesse o acordo com o hotel, prejudicando toda a comunidade.

Deste modo, o turismo na comunidade indígena Sateré-Gavião pode ser identificado em dois momentos: o início e o fim dos processos e relações advindas da atividade turística. $\mathrm{O}$ trabalho no universo turístico, por seu turno, transformou o mundo do labor em atividade de trabalho destinado a atender as necessidades do mercado capitalista, transformando às tradições para serem apresentadas para turistas. Para o tuxaua Martins (2013), com o turismo a comunidade reafirmava sua identidade, houve resgate de tradições já em desuso por estarem vivendo fora de suas áreas de origem e, por representar para os visitantes e para a sociedade de modo geral, a cultura indígena, não plenamente valorizada.

\section{CONSIDERAÇÕES FINAIS}

O objetivo deste estudo foi mostrar o processo de ressignificação das tradições indígenas da comunidade Sateré-Gavião no igarapé do Tiú, na microbacia hidrográfica do rio Tarumã-Açú afluente do rio Negro, no município de Manaus estado do Amazonas, reproduzidas a partir das relações e inter-relações das atividades turísticas nessa comunidade. Ao mesmo tempo, destacou-se sobre a atividade turística no processo de globalização e focalização local dentro da esfera global. O estudo ainda mostrou o processo inicial e os motivos que levaram ao fim da atividade turística dentro dessa comunidade.

Julga-se pertinente salientar que apresentar a temática de desenvolvimento do turismo em comunidades indígenas no meio acadêmico, onde ainda não existem muitas pesquisas orientadas para estas questões é um desafio. Necessita da seleção de um referencial teórico consistente e adequado e de superar questões relacionadas à 
burocracia que impedem de revelar à sociedade os problemas encontrados em comunidades ou terras indígenas. Por outro lado, o turismo destaca-se como uma área de saberes científicos dignos de serem igualadas as ciências humanas e sociais, uma vez que sua evolução encontra-se em constante consolidação.

Essas questões não impedem de tecer, por meio do olhar interdisciplinar às várias formas de transformação, sejam elas culturais ou ambientais e, até mesmo dos vários sistemas de trabalho. Neste universo em que a atividade turística encontra-se, existe uma diversidade de temas que podem ser descritos em pesquisas em diferentes disciplinas. Embora este estudo, por meio do olhar interdisciplinar pode identificar a transformação das tradições com finalidade para uma atividade capitalista, que é o turismo, ainda existe um longo percurso para buscar sua maior compreensão.

Subentende-se por meio da etnografia, que a escolha dos comunitários em trabalhar o turismo gerou possibilidades de desenvolver estudos sobre os significados encontrados nas relações existentes entre turistas/empreendimentos/comunidades diante das transformações culturais, sociais e do trabalho tradicional em trabalho material para o mercado turístico.

A cultura indígena está se "coisificando" ou tornando-se mercadoria como estratégia de sobrevivência para os grupos étnicos que vivem nas periferias e no entorno das grandes cidades ${ }^{13}$. Para Adorno (2009, p. 84), “o ser não deve ser absolutamente uma coisa e, não obstante, como as metáforas sempre o indicam uma vez mais, deve ser o 'solo', algo firme”. Isso não significa que o turismo está levando ao etnocídio dos grupos étnicos, ao contrário, é através dele que eles reacendem os seus valores culturais.

Com apresentação da cultura indígena para o turismo, os comunitários se uniam para buscar um bem comum, levando a cabo o significado da palavra comunidade. Por outro lado, o equilíbrio das relações ambientais dentro do sistema turístico só estaria equilibrado, se instâncias públicas mediassem as ações de entrada e saída de turistas e visitantes e estabelecessem estratégias para o desenvolvimento dessas comunidades.

Para que esse fato ocorra, sugere-se que seria necessário por intermédio da Empresa Estadual de Turismo do Amazonas (AMAZONASTUR), com o apoio do Serviço Brasileiro de Apoio às Micro e Pequenas Empresas (SEBRAE) e do Serviço

\footnotetext{
${ }^{13}$ Adorno (2002, p. 63) escreve que, quando se aceita como verdadeiro o pensamento de Marx, de que na sociedade burguesa a força de trabalho tornou-se mercadoria e, por isso, o trabalho foi coisificado.
} 
Nacional de Aprendizagem Comercial (SENAC), assim como de outros sistemas de formação profissional, a profissionalização destes atores sociais. Deste modo, a comunidade conseguiria gerir os recursos advindos das relações econômicas mediante a atividade turística.

\section{REFERÊNCIAS}

ADORNO, T. W. 1903-1969. Indústria cultural e sociedade. Tradução: Juba Elizabeth Levy. São Paulo: Terra e Paz, 2002.

Zahar, 2009.

Dialética negativa. Tradução: Marco Antônio Casanova. Rio de Janeiro:

AMAZONAS, Secretaria de Planejamento do Estado do Amazonas - SEPLAN (2011). Anuário Estatístico 2011. Disponível em: <http://www.srmm.am.gov.br>. Acesso em: 10/06/2011.

ARARA, Fruits Du Brésil: Jenipapo, 2013. Disponível em: <http://www.arara.fr /BBJENIPAPO.html>. Acesso em: 21/12/2013.

ARENDT, H. 1906-1975. A condição humana. Tradução: Roberto Raposo, posfácio de Celso Lase. 10 ed. Rio de Janeiro: Forense Universitária, 2007.

BARRETTO, M. Manual de iniciação ao estudo do turismo. 13. ed. Campinas: Papirus, 2003.

BATISTA, D. O complexo da Amazônia: análise do processo de desenvolvimento. 2. ed. Manaus: Valer, Edua e IMPA, 2007.

BENCHIMOL, S. Amazônia: Formação Social e Cultural. Manaus: Editora Valer/ Editora da Universidade do Amazonas, 1999.

BENI, M. C. Análise estrutural do turismo. São Paulo: Editora Senac, 1998.

BERNAL, R. J. Índios Urbanos: processo de reconformação das identidades étnicas indígenas em Manaus. Tradução: Evelyne Marie Therese Mainbourg. Manaus: Editora da Universidade Federal do Amazonas/ Faculdade Salesiana Dom Bosco, 2009.

BONALD NETO, O. Planejamento e organização do espaço turístico. 3. ed. Recife: FASA, 1995.

BORDIEU, P. O poder simbólico. Tradução Fernando Tomaz. 11. ed. Rio de Janeiro: Bertrand Brasil, 2007. 
BOUlLÓN, R. C. Planificacion del espacio turístico. México: Trilhas, 1997.

BRASIL, LEI N ${ }^{\circ}$ 6.001, DE 19 DE DEZEMBRO DE 1973. Estatuto do Índio. Disponível em: <http://www.funai.gov.br/projetos/Plano_editorial/Pdf/Legis4/Cap1Legislacao_Funda mental.pdf $>$. Acesso em: 24/06/2012.

BRASIL. Ministério do Desenvolvimento, Indústria e Comércio. Metodologia de gestão para adensamento de cadeias produtivas. Brasília: MDIC: Sebrae, 2000.

CAPRA, F. O ponto de mutação. Tradução: Álvaro Cabral. São Paulo: Cultrix, 2006.

CARDOSO DE OLIVEIRA, R. O trabalho do Antropólogo. 2. ed. Brasília: Paralelo 15; São Paulo: Editora Unesp, 2006.

CHIZZOTTI, A. Pesquisa em ciências humanas e sociais. 5. ed. São Paulo: Cortez, 2001.

COSTA NOVO, C. B. M. Turismo de base comunitária na Região Metropolitana de Manaus (AM): caracterização e análise crítica. São Paulo: USP, 2011. Disponível em: <http://www.teses.usp.br/teses/disponiveis/8/8136/tde-28062012-165759/pt-br.php>.

Acesso em: 13/01/2013.

GEERTZ, C. A interpretação das culturas. 1. ed. Rio de Janeiro: LTC, 2008.

GOELDNER, C R. Turismo: princípios práticas e filosofias. Tradução: Roberto Cataldo Costa. 8. ed. Porto Alegre: Bookman, 2002.

GONDIM, N. A invenção da Amazônia. São Paulo: Marco Zero, 1994.

GRÜNEWALD, R de A. Índios do descobrimento: tradições e turismo. Rio de Janeiro: Contra Capa Livraria, 2001.

JULIANO, T.; RABINOVICI, A. Turismo em terras indígenas. In: NEIMAN, Z.; RABINOVICI, A. Turismo e Meio Ambiente no Brasil. Barueri, São Paulo: Manole, 2010.

HALL, S. A identidade cultural na pós-modernidade. Tradução: Tomaz Tadeu da Silva; Guaracira Lopes Louro. 11. ed. Rio de Janeiro. DP\&A, 2006.

HOUAISS, A. Dicionário eletrônico Houaiss da língua portuguesa 2.0a. Rio de Janeiro: Ed. Objetiva Ltda, 2007.

KAPFHAMMER, W. De "Sateré Puro" (Sateré Sese) ao "Novo Sateré" (Sateré Pakup): Mitopráxis no movimento evangélico entre os Sateré-Mawé. In: Wright, Robin M. (org.): Transformando os Deuses: Igrejas Evangélicas, Pentecostais e Neopentecostais entre os Povos Indígenas no Brasil, Volume II. Campinas: Editora Unicamp, 2004, 134193. 
KRIPPENDORF, J. Sociologia do turismo: para uma nova compreensão do lazer e das viagens. 3. ed. São Paulo: Aleph, 2001.

LEAL, R. E. da S. O turismo desenvolvido em territórios indígenas sob o ponto de vista antropológico. In: BARTHOLO, R; SANSOLO, D G; BURSZTYN, I (Org.). Turismo de Base Comunitária; diversidade de olhares e experiências brasileiras. RJ: Letra e Imagem, 2009.

MAURO, V. F. Turismo em Terra Indígena: o caso da Reserva Pataxó da Jaqueira. Brasília, 2007. Disponível em: <http://bdm.bce.unb.br/bitstream/10483/259/1/2007_ VictorFerriMauro.pdf>. Acesso em: 18/07/2013.

MARTINS, E. da S. Entrevista: comunidade Sateré-Gavião. Manaus, 2013.

ONU, Organização das Nações Unidas. Declaração das Nações Unidas sobre os Direitos dos Povos Indígenas, 2006. Disponível em: <http://www.funai.gov.br/ projetos/Plano_editorial/Pdf/Legis4/Cap1-Legislacao_Fundamental.pdf>. Acesso em: 24/06/2012.

PEIXOTO, S. C. P. de S.; ALBUQUERQUE, C. C. de. Turismo étnico indígena: Meio de sustentabilidade para os índios urbanos da cidade de Manaus. Revista Eletrônica Aboré. Publicação da Escola Superior de Artes e Turismo. Manaus, n. 3, nov. 2007. ISSN 1980-6930. Disponível em: <http://www.revistas.uea.edu.br/old/abore/artigos /artigos_3/Shirley\%20Cintra\%20Portela\%20de\%20Sa\%20Peixoto.pdf $>$. Acesso em: 24/09/2010.

RIBEIRO, D. Os índios e a civilização: a integração das populações indígenas no Brasil moderno. São Paulo: Companhias da Letras, 1996.

RODRIGUES, A. M. Desenvolvimento sustentável e atividade turística. In: RODRIGUES, A. B. (Org.). Turismo e desenvolvimento local. 2. ed. São Paulo: Hucitec, 1999.

SANTOS, B. de S. Pela mão de Alice. O social e o político na transição pós-moderna. São Paulo: Cortez, 1997.

A crítica da razão indolente: contra o desperdício da experiência. 4. ed. São Paulo: Cortez, 2002.

SANTOS, M. Por uma outra globalização: do pensamento único à consciência universal. 6. ed. Rio de Janeiro/ São Paulo: Editora Record, 2001.

SILVA, M. C. da. O Paiz do Amazônas. 3. ed. Manaus: Editora Valer, 2012.

SILVA, G. P. da. Estudos sobre a realização de atividades Turísticas nas terras indígenas brasileiras. Brasilia: FUNAI, 2008. Disponível em: <http://ciede.mgt.unm. edu/fibea2008/papers/Ecotourism/dasilvapaper.pdf>. Acesso em: 01/06/2013. 
SOUZA, M. J. L. de. Como pode o turismo contribuir para o desenvolvimento local? In: RODRIGUES, A B. Turismo e desenvolvimento local. 2. ed. São Paulo: Hucitec, 1999.

TORRES, I. C. As Novas Amazônidas. Manaus: Editora da Universidade Federal do Amazonas, 2005.

VIVATERRA, Palmeiras nativas do Brasil: bacuri, 2013. Disponível em: <http://www.vivaterra.org.br/palmeiras_nativas.htm\#bacuri>. Acesso em: 21/12/2013.

WEBER, M. 1864-1920. A ética protestante e o "espírito" do capitalismo. Tradução: Marcos Mariani de Macedo. São Paulo: Companhia das Letras, 2004.

Recebido em: 30-07-2013

Aprovado em: 29-08-2013. 